Check for updates

Cite this: RSC Adv., 2019, 9, 33643

Received 5th August 2019

Accepted 10th October 2019

DOI: $10.1039 / c 9 r a 06068 \mathrm{e}$

rsc.li/rsc-advances

\section{Scalable nanohybrids of graphitic carbon nitride and layered NiCo hydroxide for high supercapacitive performance $\uparrow$}

\author{
Bebi Patil, ${ }^{a}$ Changyong Park ${ }^{\mathrm{b}}$ and Heejoon Ahn (D) *ab
}

The limited number of edge nitrogen atoms and low intrinsic electrical conductivity hinder the supercapacitive energy storage applications of the nitrogen-rich graphitic carbon nitride $\left(\mathrm{g}-\mathrm{C}_{3} \mathrm{~N}_{4}\right)$. In this study, a novel graphitic carbon nitride/NiCo-layered double hydroxide (CNLDH), a two-dimensional nanohybrid, is prepared by a simple hydrothermal synthesis. The homogeneous interpolation of $g-C_{3} N_{4}$ nanosheets into NiCo LDH stacked nanosheets effectively increases the overall performances of the g$\mathrm{C}_{3} \mathrm{~N}_{4} / \mathrm{NiCo} \mathrm{LDH}$ nanohybrid. The improved morphology of the nanohybrid electrode upon the addition of $\mathrm{g}-\mathrm{C}_{3} \mathrm{~N}_{4}$ to the $\mathrm{NiCo} \mathrm{LDH}$ yields a specific capacity of $183.43 \mathrm{~mA} \mathrm{~h} \mathrm{~g}^{-1}$ in $6 \mathrm{M} \mathrm{KOH}$ at $1 \mathrm{~A} \mathrm{~g}^{-1}$, higher than those of bare $\mathrm{g}-\mathrm{C}_{3} \mathrm{~N}_{4}\left(20.89 \mathrm{~mA} \mathrm{~h} \mathrm{~g}^{-1}\right)$ and $\mathrm{NiCo} \mathrm{LDH}\left(95.92 \mathrm{~mA} \mathrm{~h} \mathrm{~g}^{-1}\right)$ electrodes. The excellent supercapacitive performance of the CNLDH nanohybrid is complemented by its low internal resistance, excellent rate capability, and large cycling lifetime. Furthermore, the hybrid supercapacitor is assembled using CNLDH 0.1 as a positive electrode and activated carbon (AC) as a negative electrode. The hybrid supercapacitor device of CNLDH 0.1//AC shows the maximum specific capacity of $37.44 \mathrm{~mA} \mathrm{~h} \mathrm{~g}^{-1}$ at $1 \mathrm{~A} \mathrm{~g}^{-1}$ with remarkable energy density, power density and good cycling performance. This confirms that the CNLDH 0.1 nanohybrid is an excellent electrode material for supercapacitor applications.

\section{Introduction}

Energy storage technologies involving supercapacitors require high energy and power densities. ${ }^{1}$ To achieve this aim, extensive studies have been carried out on the development of new electrode materials that are superior to the existing class of metal oxides, carbon materials, conducting polymers, etc. ${ }^{2-4}$ Depending on the structures of the electrodes, the supercapacitors fundamentally operate based on two mechanisms, electrochemical double-layer capacitance and pseudo-capacitance, storing energy by charge accumulation at the electrode-electrolyte interface and by fast and reversible surface redox reactions, respectively. ${ }^{5}$ Regarding the material design, the development of hybrid nanostructures with different properties by combining various building blocks into newly designed structures has attracted large interest. The combination of two different nanostructures with distinct physical and chemical properties into a new hybrid with a unique structure can usually inherit cumulative advantages of the individual materials or even lead to the formation of a new heterostructured material

${ }^{a}$ Institute of Nano Science and Technology, Hanyang University, Seoul 04763, South Korea.E-mail: ahn@hanyang.ac.kr

${ }^{b}$ Department of Organic and Nano Engineering, Hanyang University, Seoul 04763, South Korea

† Electronic supplementary information (ESI) available. See DOI: 10.1039/c9ra06068e with better properties. In recent years, the syntheses of different two-dimensional (2D) layered materials, such as graphene, hexagonal boron nitride, layered double hydroxides (LDHs), carbon nitride, MXenes, and transition metal dichalcogenides, have attracted considerable attention for the development of energy materials having unique properties. ${ }^{6-9}$ The $2 \mathrm{D}$ layered structures of these materials provide metallic or semiconducting properties. ${ }^{10}$ The $2 \mathrm{D}$ layered structures have advantages over bulk materials, such as the facilitated intercalation/deintercalation of ions and volume expansion, ${ }^{\mathbf{1 1}}$ and thus have been employed in various applications, such as sensing, ${ }^{12}$ electrochemical energy storage and conversion, ${ }^{13}$ catalysis, ${ }^{\mathbf{1 4}}$ and transistors. ${ }^{15}$ The increased interlayer distance in 2D layered materials is advantageous for energy storage as it can facilitate the ion transport and provide a better tolerance to the volume change, unlike in bulk materials. ${ }^{16}$ Additionally, the large surface area and number of active sites in 2D layered materials make them desirable for use as energy storage devices.

Despite the extensive studies on 2D layered materials, their functionality should be improved. A novel approach for this purpose is the development of heterostructures of organicinorganic 2D layered materials. This approach can pave the way for the development of novel electrodes with increased electrochemical performances by combining the advantages of the individual building blocks while eliminating their shortcomings. To demonstrate our concept, we hybridize 2D graphitic 
carbon nitride $\left(\mathrm{g}-\mathrm{C}_{3} \mathrm{~N}_{4}\right)$ and $\mathrm{LDH}$ of nickel-cobalt (NiCo). g$\mathrm{C}_{3} \mathrm{~N}_{4}$, a nanocarbon material consisting of two earth-abundant elements (carbon and nitrogen), is a novel 2D layered organic semiconductor ${ }^{17}$ which has attracted increasing interest owing to its layered structure, simple synthesis, and low synthesis cost. The LDHs, such as the NiCo LDHs, are a class of 2D inorganic layered matrices consisting of positively charged layers, with anions and water molecules intercalated in the interlayer region. The $2 \mathrm{D}$ NiCo $\mathrm{LDH}$ provides a short ion diffusion path, abundant active sites, and different valence states, resulting in an increased electrochemical performance. ${ }^{18,19}$ However, the limited electroactive sites, low conductivity, low cycling stability of the NiCo $\mathrm{LDH}$, and low ion transport capability of g- $\mathrm{C}_{3} \mathrm{~N}_{4}$ hinder the applications of both materials. To overcome the disadvantages of these materials, we develop integrated heterostructures of $\mathrm{g}-\mathrm{C}_{3} \mathrm{~N}_{4}$ with $\mathrm{NiCo} \mathrm{LDH}$ by successfully coupling them. This concept elucidates the specific challenges that need to be addressed for the introduction of $2 \mathrm{D}$ heterostructured electrodes into next-generation energy storage devices.

\section{Experimental methods}

\section{Materials}

Analytically pure urea, nitric acid $\left(\mathrm{HNO}_{3}\right)$, absolute ethanol (99\%), nickel nitrate $\left(\mathrm{Ni}\left(\mathrm{NO}_{3}\right)_{2} \cdot 6 \mathrm{H}_{2} \mathrm{O}\right)$, cobalt nitrate $\left(\mathrm{Co}\left(\mathrm{NO}_{3}\right)_{2} \cdot 6 \mathrm{H}_{2} \mathrm{O}\right)$, and potassium hydroxide $(\mathrm{KOH})$ were purchased from Sigma-Aldrich. None of the materials used in the experiments were further purified, unless otherwise stated.

\section{Synthesis}

g- $\mathbf{C}_{3} \mathbf{N}_{4} \cdot g-\mathrm{C}_{3} \mathrm{~N}_{4}$ was fabricated by the simple pyrolysis of urea. ${ }^{20}$ The urea precursor ( $5 \mathrm{~g}$ ) was kept in an alumina crucible with a cover. The crucible was heated for $2 \mathrm{~h}$ at $80{ }^{\circ} \mathrm{C}$ to remove moisture and obtain an oxygen-free product. The crucible was then heated at $550{ }^{\circ} \mathrm{C}$ in the ambient air for $3 \mathrm{~h}$ at a rate of $5{ }^{\circ} \mathrm{C} \mathrm{min}^{-1}$. The resulting product was washed with $0.1 \mathrm{M}$ of nitric acid and distilled water several times and dried at $80{ }^{\circ} \mathrm{C}$ for $24 \mathrm{~h}$. A pale-yellow $\mathrm{g}-\mathrm{C}_{3} \mathrm{~N}_{4}$ powder was obtained after ultrasonication for $2 \mathrm{~h}$.

NiCo LDH. The NiCo LDH powder was synthesized by a hydrothermal method. In the typical synthesis, $0.582 \mathrm{~g}$ of $\mathrm{Ni}\left(\mathrm{NO}_{3}\right)_{2} \cdot 6 \mathrm{H}_{2} \mathrm{O}$ and $0.874 \mathrm{~g}$ of $\mathrm{Co}\left(\mathrm{NO}_{3}\right)_{2} \cdot 6 \mathrm{H}_{2} \mathrm{O}$ were dissolved in $70 \%$ ethanol. The prepared solution was transferred in a $200 \mathrm{~mL}$ Teflon autoclave and heated at $160{ }^{\circ} \mathrm{C}$ for $3 \mathrm{~h}$. During the cooling of the reaction mixture to room temperature, the resultant solution was washed with copious amounts of water and ethanol. The washed powder was kept in the vacuum oven at $60{ }^{\circ} \mathrm{C}$ for $12 \mathrm{~h}$. Different nanostructures of NiCo LDH were synthesized by varying the synthesis time $(6,8$, and $12 \mathrm{~h})$.

g- $\mathbf{C}_{3} \mathbf{N}_{4}-\mathbf{N i C o}$ LDH (CNLDH) heterostructures. The optimized NiCo LDH sample was further used for the preparation of CNLDH heterostructures. The CNLDH heterostructures were prepared by adding $0.1,0.3$, and $0.5 \mathrm{~g}$ of the as-prepared $\mathrm{g}-\mathrm{C}_{3} \mathrm{~N}_{4}$ to the $\mathrm{Ni}$ and $\mathrm{Co}$ precursors and carrying out the synthesis under the same set of conditions. The obtained products are denoted as CNLDH $0.1,0.3$, and 0.5 , respectively. Fig. 1 illustrates the hybridization of $\mathrm{g}-\mathrm{C}_{3} \mathrm{~N}_{4}$ and NiCo $\mathrm{LDH}$, carried out to form the layer-on-layer assembly of CNLDH heterostructure.

\section{Characterization}

The morphologies and microstructures of the as-obtained products were characterized by field-emission scanning electron microscopy (FESEM, JEOL 7800), transmission electron microscopy (TEM, 2100F), and high-angle annular-dark-field scanning transmission electron microscopy (HAADF-STEM, JEM-ARM 200F). X-ray diffraction (XRD; MiniFlex 600) patterns were recorded using $\mathrm{Cu} \mathrm{K}_{\alpha}$ radiation $(\lambda=0.15406 \mathrm{~nm})$. The specific surface area was calculated using the BrunauerEmmett-Teller (BET) method, while the pore size distribution was obtained using the desorption branch data by the BarrettJoyner-Halenda (BJH) method. Fourier-transform infrared (FTIR) spectroscopy was performed using a Nanofinder 3.0 Raman spectrometer at an excitation wavelength of $488 \mathrm{~nm}$. Xray photoelectron spectroscopy (XPS) was performed using a Kratos-Axis spectrometer with monochromatic Al $\mathrm{K}_{\alpha}(1486.7$ $\mathrm{eV})$ X-ray radiation $(15 \mathrm{kV}, 10 \mathrm{~mA})$. Electrochemical
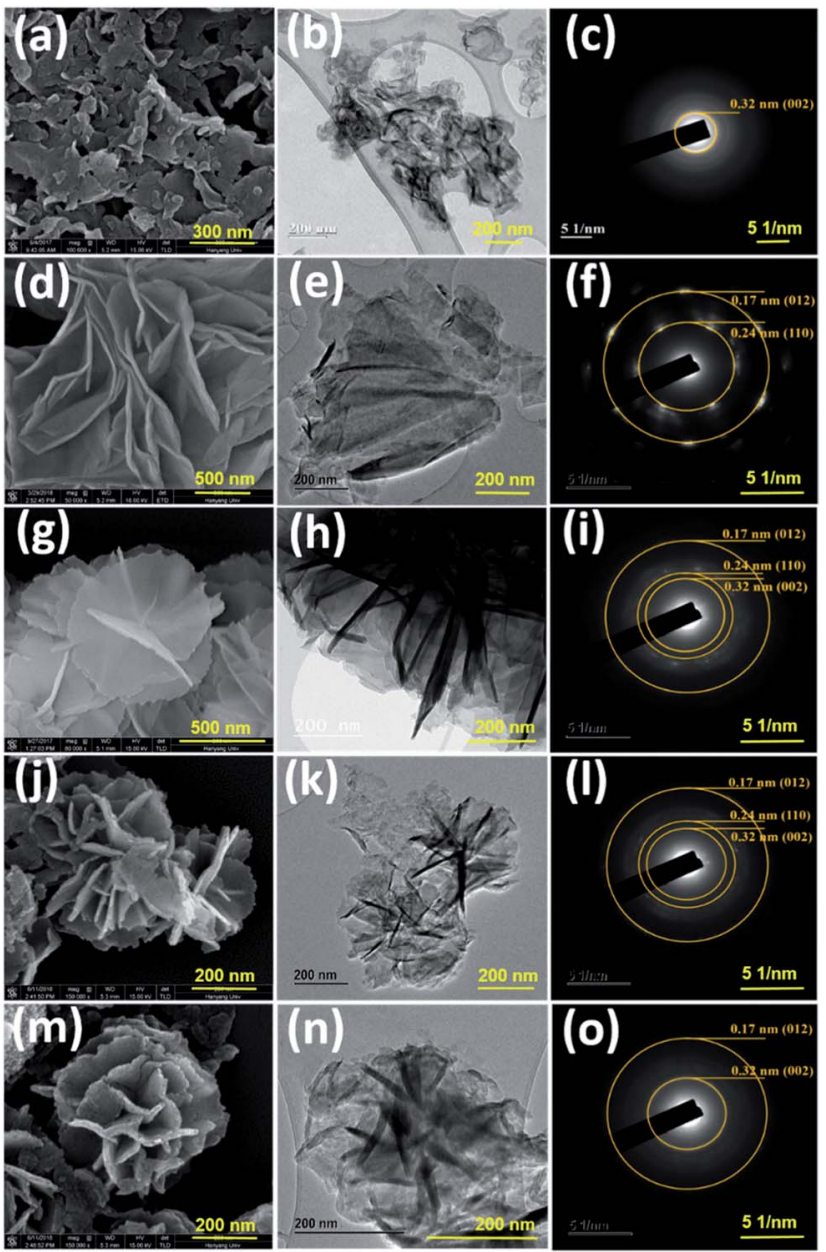

Fig. 1 SEM and TEM images and selected-area electron diffraction

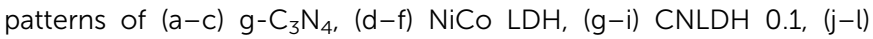
$\mathrm{CNLDH} 0.3$, and $(\mathrm{m}-\mathrm{o}) \mathrm{CNLDH} 0.5$, respectively. 
measurements of the g- $\mathrm{C}_{3} \mathrm{~N}_{4}$, NiCo LDH, and CNLDH heterostructures were carried out in a three-electrode system, in a $6 \mathrm{M}$ $\mathrm{KOH}$ aqueous solution, where $\mathrm{Hg} / \mathrm{HgO}$ and $\mathrm{Pt}$ coil were used as the reference and counter electrodes, respectively. For the fabrication of the working electrode, the active material were mixed with poly (vinylidene fluoride) (PVDF, M. W. 534 000, Sigma-Aldrich) and carbon black (Super P, TIMCAL Graphite \& Carbon) with a weight ratio of $8: 1: 1$ in $N$-methyl-2-pyrrolidone (NMP) to form a slurry. The slurry was coated onto a carbon paper current collector $\left(1 \times 1 \mathrm{~cm}^{2}\right)$ using a spatula. The prepared electrodes were dried at $110{ }^{\circ} \mathrm{C}$ for $12 \mathrm{~h}$ under vacuum. The same process followed for the preparation of activated carbon (AC) as a negative electrode for hybrid supercapacitor. The total mass of CNLDH 0.1 and AC was about $3.5 \mathrm{mg} \mathrm{cm}^{-2}$. Cyclic voltammetry (CV) and galvanostatic charge-discharge (GCD) measurements were carried out using an electrochemical workstation (ZIVE SP1, WonA Tech) in the range of 0 to $+0.5 \mathrm{~V}$ / $\mathrm{Hg} / \mathrm{HgO}$ for half-cell test and 0 to $+1.2 \mathrm{~V}$ for hybrid supercapacitor at various scanning rates and current densities. Prior to the $\mathrm{CV}$ and GCD measurements, the electrodes were activated by cycling the operation voltage for 25 cycles at $50 \mathrm{mV} \mathrm{s}^{-1}$. The ion kinetics within the electrode material were investigated by electrochemical impedance spectroscopy (EIS) in a frequency range of 0.01 to $10^{5} \mathrm{~Hz}$ at the open-circuit potential. The specific capacity $\left(C_{\mathrm{sp}}, \mathrm{mA} \mathrm{h} \mathrm{g}{ }^{-1}\right)$, energy density $\left(E, \mathrm{~W} \mathrm{~h} \mathrm{~kg}^{-1}\right)$ and power density $\left(P, \mathrm{~W} \mathrm{~kg}^{-1}\right)$ were calculated using the GCD curve,

$$
\begin{aligned}
& C_{\mathrm{sp}}=I \Delta t / m, \\
& E=I \Delta t V / m,
\end{aligned}
$$

and

$$
P=E / \Delta t
$$

where $I(\mathrm{~mA}), t(\mathrm{~h}), V(\mathrm{~V})$ and $m(\mathrm{~g})$ are the discharging current, time, voltage and mass of active material, respectively.

\section{Results and discussion}

\section{SEM}

The morphologies of the as-prepared nanostructures were characterized by FESEM and TEM. The SEM images of the NiCo
LDHs in Fig. S1† reveal the separation of the LDH nanosheets with the increase in hydrothermal synthesis time. Typically, collective nanosheets with a thickness of $\sim 90 \mathrm{~nm}$ are formed by the synthesis for $3 \mathrm{~h}$, whereas vertically aligned nanosheets having a thickness of $\sim 30 \mathrm{~nm}$ are obtained by the synthesis for $12 \mathrm{~h}$ (Fig. S1 $\dagger$ ). These thin nanosheets are densely interconnected with each other forming a highly porous network (Scheme 1).

The nanoporous structure could be beneficial to increase the electrochemical performance of the LDH. Therefore, the NiCo LDH obtained with the synthesis time of $12 \mathrm{~h}$ was considered ideal for the further preparation of CNLDH nanohybrids. The morphologies of the $\mathrm{g}_{-} \mathrm{C}_{3} \mathrm{~N}_{4}$, NiCo LDH, CNLDH 0.1, CNLDH 0.3 , and CNLDH 0.5 nanohybrids are presented in Fig. 1. The SEM image in Fig. 1a shows the lamellar crumpled silk-like structure of $\mathrm{g}-\mathrm{C}_{3} \mathrm{~N}_{4}{ }^{21}$ As shown in Fig. $1 \mathrm{~b}$ and $\mathrm{c}$, the lamellar structure of $\mathrm{g}-\mathrm{C}_{3} \mathrm{~N}_{4}$ exhibits a lattice spacing of $0.32 \mathrm{~nm}$ corresponding to the (002) reflection of the graphitic structure of carbon nitride, which corroborates the XRD results. Fig. 1d-f shows the hydrothermally synthesized polycrystalline thin sheets of NiCo hydroxide. Notably, upon the introduction of the as-prepared $\mathrm{g}-\mathrm{C}_{3} \mathrm{~N}_{4}$ nanosheets in the hydrothermal autoclave, the CNLDH hybrid nanosheets could be synthesized in the form of "sheet-on-sheet" structure. In CNLDH 0.1 (Fig. 1g-i), the NiCo LDH and g- $\mathrm{C}_{3} \mathrm{~N}_{4}$ are well intercalated. The g- $\mathrm{C}_{3} \mathrm{~N}_{4}$ can effectively reduce the dimensions of the nanosheets by forming ultrathin nanolayers (CNLDH 0.1; Fig. $1 \mathrm{~g}$ and $\mathrm{h}$ ). Such structure could provide excellent electron-diffusion paths facilitating the diffusion and migration of electrolyte ions within the electrode materials and enhancing the electrochemical behavior of the nanohybrid. ${ }^{22}$ The morphological analyses suggest that with the increase in content of g- $\mathrm{C}_{3} \mathrm{~N}_{4}$, LDH nanoflowers seem to grow on $\mathrm{g}-\mathrm{C}_{3} \mathrm{~N}_{4}$ nanosheets at the expense of the crystallinity (Fig. $1 \mathrm{j}$ o). Such behavior has been also reported for an LDH/graphene oxide composite having a layer-on-layer structure. ${ }^{23}$

\section{HAADF STEM}

CNLDH 0.1 was investigated by HAADF-STEM. The elemental maps (Fig. 2c) show the uniform distributions of $\mathrm{C}$ and $\mathrm{N}$ elements. The TEM image (Fig. 2a) of CNLDH 0.1 shows that ultrathin NiCo LDH nanosheets densely cover the surface of $\mathrm{g}$ $\mathrm{C}_{3} \mathrm{~N}_{4}$ (outlined by red dashed lines). The firmly immobilized

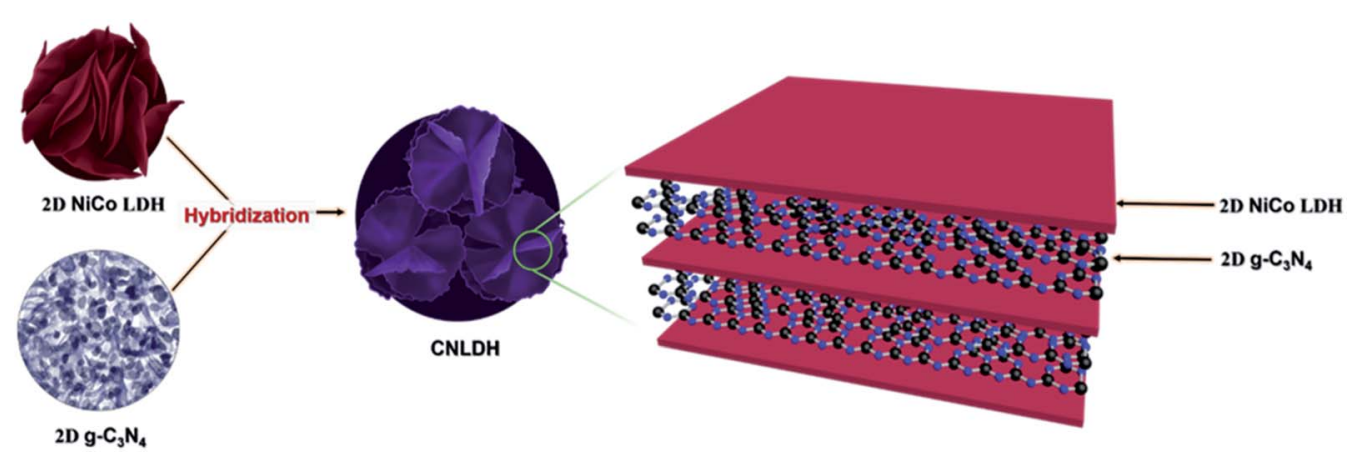

Scheme 1 Schematic of the fabrication of the CNLDH nanohybrid. 
NiCo LDH nanosheets obtained during the TEM specimen preparation remained unseparated for days, indicative of a strong interaction between $\mathrm{g}-\mathrm{C}_{3} \mathrm{~N}_{4}$ and NiCo LDH. The highresolution TEM image in Fig. $2 \mathrm{~b}$ shows the calculated lattice spacings of the nanosheets of approximately 0.24 and $0.47 \mathrm{~nm}$, corresponding to the (110) and (006) planes of the NiCo LDH, respectively, and that of $0.32 \mathrm{~nm}$, corresponding to the (002) planes of $\mathrm{g}-\mathrm{C}_{3} \mathrm{~N}_{4}$. Energy-dispersive X-ray spectroscopy (EDS) mapping was carried out to determine the compositional and elemental distributions; the results are shown in Fig. 2c. The uniform distributions of the characteristic elements $\mathrm{C}, \mathrm{N}, \mathrm{Ni}$, $\mathrm{Co}$, and $\mathrm{O}$ in the EDS maps demonstrate the presence of $\mathrm{g}-\mathrm{C}_{3} \mathrm{~N}_{4}$ nanosheets between the layers of the NiCo LDH. Such unique $2 \mathrm{D}$ heterostructure can provide more electrochemically active sites for the exposure to the electrolyte, favoring the ion transfer and diffusion and accelerating the surface redox reaction. ${ }^{24}$

\section{XRD}

The sharp peaks in the XRD patterns of the NiCo LDHs obtained using different hydrothermal synthesis times (Fig. S2 $\dagger$ ) indicate the considerable crystallinities of the as-synthesized NiCobased hydroxide samples, which is attributed to the hydrothermal reaction environment that is carefully engineered for crystal growth. Moreover, the absence of other peaks related to side reactions and impurities reflects the high purity of the designed reaction. ${ }^{25}$ As $\mathrm{Ni}$ and Co hydroxides have similar structures, the differentiation of the two phases was not simple.
The diffraction peaks around $11^{\circ}, 23^{\circ}, 33^{\circ}, 34^{\circ}$, and $61^{\circ}$ are attributed to the (003), (006), (220), (012), and (113) planes of $\alpha$ $\mathrm{Co}(\mathrm{OH})_{2}$ and $\alpha-\mathrm{Ni}(\mathrm{OH})_{2}$ (Joint Committee on Powder Diffraction Standards (JCPDS) 460605 and 380717, respectively). The $2 \theta$ diffraction peak at $11.6^{\circ}(0.76 \mathrm{~nm})$ corresponds to both $\alpha$ $\mathrm{Co}(\mathrm{OH})_{2}$ and $\alpha-\mathrm{Ni}(\mathrm{OH})_{2}$. The stacking of the layers along the $c$ axis indicates the difference between the $\alpha$ - and $\beta$-phases. The $\mathrm{Co}(\mathrm{OH})_{2}$ and $\mathrm{Ni}(\mathrm{OH})_{2}$ layers are randomly oriented and separated by intercalated water molecules bonded to the hydroxyl groups by hydrogen bonds in the $\alpha$-phase with an interlamellar distance of approximately $0.8 \mathrm{~nm}$. In the $\beta$-phase, $\mathrm{Co}(\mathrm{OH})_{2}$ and $\mathrm{Ni}(\mathrm{OH})_{2}$ layers are perfectly stacked along the $c$-axis with an interlamellar distance of $0.4 \mathrm{~nm}$ without intercalated species. $\alpha$ phase compounds are theoretically expected to exhibit superior electrochemical activities to those of the $\beta$-phase compounds. ${ }^{26}$ The peak at $19.38^{\circ}$ observed for the sample synthesized for $12 \mathrm{~h}$ corresponds to the (001) plane and confirms the layered structure of the synthesized NiCo hydroxide.

Fig. 3a shows the XRD patterns of the NiCo $\mathrm{LDH}, \mathrm{g}-\mathrm{C}_{3} \mathrm{~N}_{4}$, and $\mathrm{CNLDH}$ nanohybrids. The peaks at $12.74^{\circ}$ and $27.43^{\circ}$ observed for $\mathrm{g}-\mathrm{C}_{3} \mathrm{~N}_{4}$ can be indexed to the (210) and (002) planes (JCPDS 000660813), corresponding to the in-plane structural packing of tri-s-triazine units with a distance of $0.68 \mathrm{~nm}$ and periodic interlayer stacking of aromatic segments with a distance of $0.32 \mathrm{~nm}$ in the conjugated aromatic system, respectively. The peaks corresponding to the (002) plane are usually attributed to the distance between the layers of the

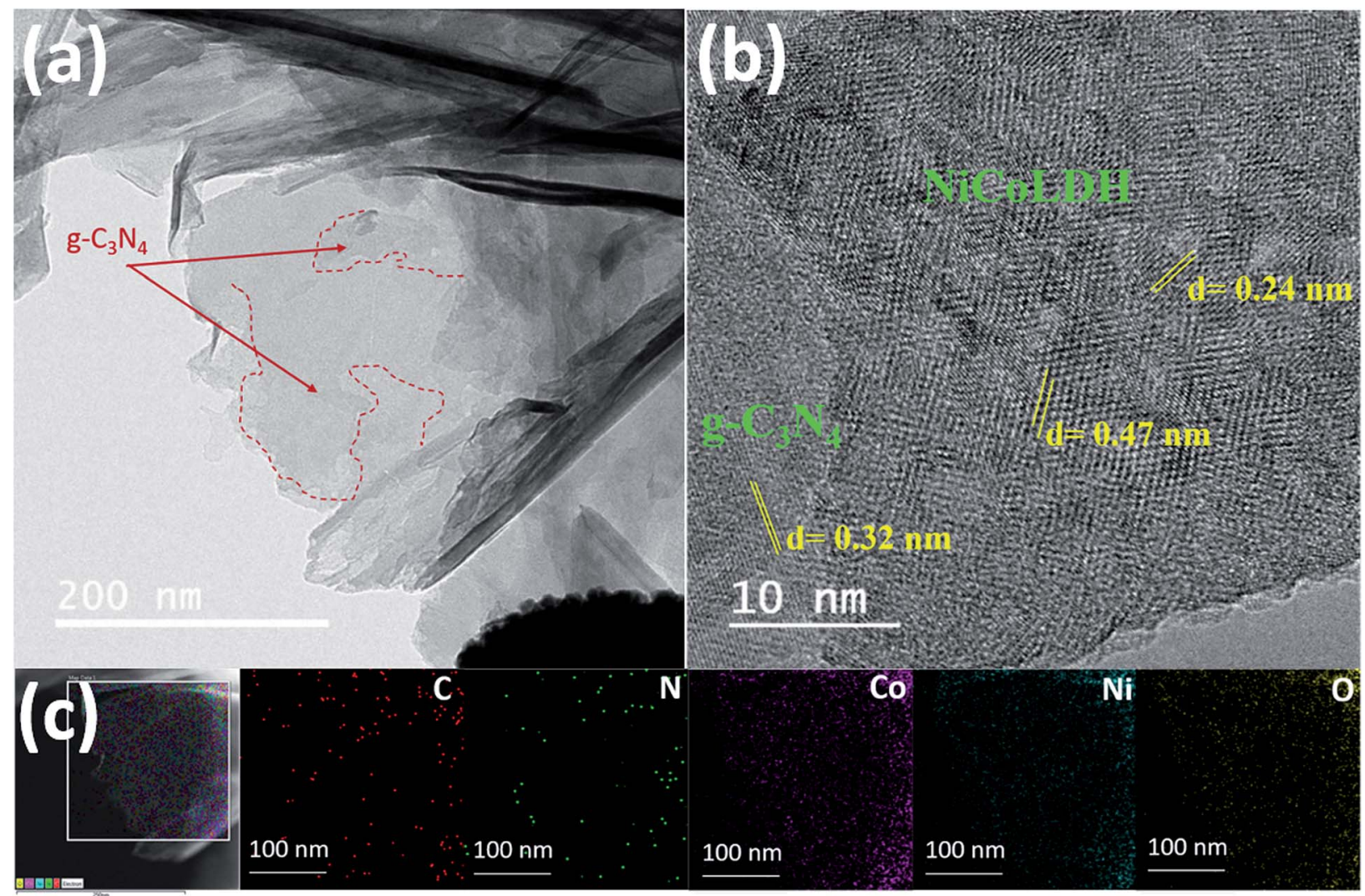

Fig. 2 (a) TEM and (b) HAADF-STEM images and (c) elemental maps of CNLDH 0.1. 
graphitic material; however, for $\mathrm{g}-\mathrm{C}_{3} \mathrm{~N}_{4}$, the peaks corresponding to the (210) plane are attributed to the intralayer $d$ spacing. ${ }^{27}$ In addition, the $d$-spacing of the (002) plane of CNLDH 0.1 suggests that $\mathrm{g}-\mathrm{C}_{3} \mathrm{~N}_{4}$ is intercalated between the LDH layers. Further, the high-angle (2 $\theta)$ shifts of the (002) XRD peaks of the LDH composites (Fig. S3a $\dagger$ ) indicate decreased stacking distances and reveal that the packing density of g$\mathrm{C}_{3} \mathrm{~N}_{4}$ and $\mathrm{LDH}$ perpendicular to the layer direction is higher. This is attributed mainly to the van der Waals interaction between two adjacent layers. ${ }^{28}$ The left shift of the (003) diffraction peak (Fig. $\mathrm{S} 3 \mathrm{~b} \dagger$ ) reflects the increased crystal lattice spacing of the $\mathrm{LDH}$ owing to the intercalation of $\mathrm{g}-\mathrm{C}_{3} \mathrm{~N}_{4}$, showing that the CNLDH structure is a hybrid consisting of two phases. In addition, as shown in Fig. S3a, $\uparrow$ the intensity of the characteristic (002) diffraction peak of $\mathrm{g}-\mathrm{C}_{3} \mathrm{~N}_{4}$ increases with an increase in the content of $\mathrm{g}-\mathrm{C}_{3} \mathrm{~N}_{4}$ in the $\mathrm{CNLDH}$ hybrid, reflecting the intercalation of $\mathrm{g}-\mathrm{C}_{3} \mathrm{~N}_{4}$ in the NiCo LDH nanostructure, which increased the interlayer spacing. ${ }^{\mathbf{2 9 , 3 0}}$

\section{FTIR spectroscopy}

The functional groups in the prepared samples (NiCo LDH, g$\mathrm{C}_{3} \mathrm{~N}_{4}$, and $\mathrm{CNLDH}$ nanohybrids) are analyzed by FTIR spectroscopy (Fig. 3b). The narrow band around $3634 \mathrm{~cm}^{-1}$ in the FTIR spectrum of the NiCo LDH sample corresponding to the stretching vibration of $\mathrm{OH}^{-}$groups reflects the replacement of the carboxyl organic ligand by $\mathrm{OH}^{-} .^{31}$ The characteristic bands of the NiCo LDH at 3454 and $1630 \mathrm{~cm}^{-1}$ originate from the $\mathrm{O}-\mathrm{H}$ stretching vibration and bending modes of the interlayer water and hydroxyl group, respectively. The band at $1383 \mathrm{~cm}^{-1}$ is assigned to the vibration of interlayer $\mathrm{CO}_{3}{ }^{2-}$ and $\mathrm{NO}_{3}{ }^{-}$anions. $\mathrm{CO}_{3}{ }^{2-}$ participated in the formation of the nickel cobalt carbonate hydroxide hydrate with $\mathrm{Ni}^{2+}$ and $\mathrm{Co}^{2+}$ ions through coordinate bonds, while $\mathrm{NO}_{3}{ }^{-}$was retained in the interlayer LDH. ${ }^{32}$ Furthermore, the additional absorption signals under $1000 \mathrm{~cm}^{-1}$ are attributed to the stretching and bending vibrations of Ni-O-H and Co-O-H in the LDH. ${ }^{33}$ The FTIR spectrum of $\mathrm{g}-\mathrm{C}_{3} \mathrm{~N}_{4}$ shows a broad absorption peak at $3000-3600 \mathrm{~cm}^{-1}$ attributed to the stretching vibrations of $\mathrm{N}-\mathrm{H}$ groups. The typical stretching modes of $\mathrm{CN}$ heterocycles are observed in the range of $1200-1650 \mathrm{~cm}^{-1}$, while the absorption at $810 \mathrm{~cm}^{-1}$ is assigned to tri-s-triazine, i.e., to the breathing mode of triazine. ${ }^{34}$ The FTIR spectra are in good agreement with the previous results on $\mathrm{g}-\mathrm{C}_{3} \mathrm{~N}_{4}$ materials prepared by polycondensation and polymerization reactions. ${ }^{35,36}$ Notably, with the increase in $\mathrm{g}-\mathrm{C}_{3} \mathrm{~N}_{4}$ content in the $\mathrm{LDH}$, the stretching vibrations of the $\mathrm{CN}$ heterocycles are observed along with the breathing mode of triazine in the FTIR spectrum of the hybrid, which suggests the hybridization of $\mathrm{g}-\mathrm{C}_{3} \mathrm{~N}_{4}$ and ultrathin NiCo LDH nanosheets. ${ }^{37}$ The FTIR spectra reveal the CN structure on the surface of the $\mathrm{LDH}$ and strong electrostatic bonding interaction between $\mathrm{g}-\mathrm{C}_{3} \mathrm{~N}_{4}$ and $\mathrm{LDH}$.

\section{XPS}

The XP survey spectra of g- $\mathrm{C}_{3} \mathrm{~N}_{4}$, NiCo LDH, and CNLDH 0.1 in Fig. 4a reveal the presence of $\mathrm{C}$ and $\mathrm{N}$ in $\mathrm{CNLDH}$ 0.1. The XP survey spectrum of $\mathrm{g}-\mathrm{C}_{3} \mathrm{~N}_{4}$ shows high $\mathrm{C} 1 \mathrm{~s}$ and $\mathrm{N}$ 1s peaks and small $O$ is peak corresponding to an atomic ratio of 42.8 : $55.7: 1.5$. The high-resolution $C 1$ s spectrum in Fig. $4 \mathrm{~b}$ can be fitted by Gaussian curves with dominant components centered at 287.7, 285.9, and $284.6 \mathrm{eV}$, attributed to $\mathrm{C}-\mathrm{N}-\mathrm{C}, \mathrm{C}-$ $\mathrm{OH}$, and $\mathrm{sp}^{2} \mathrm{C}-\mathrm{C}$ bonds of graphitic carbon, respectively. Similarly, the N 1s peak (Fig. 4c) can be deconvoluted into three
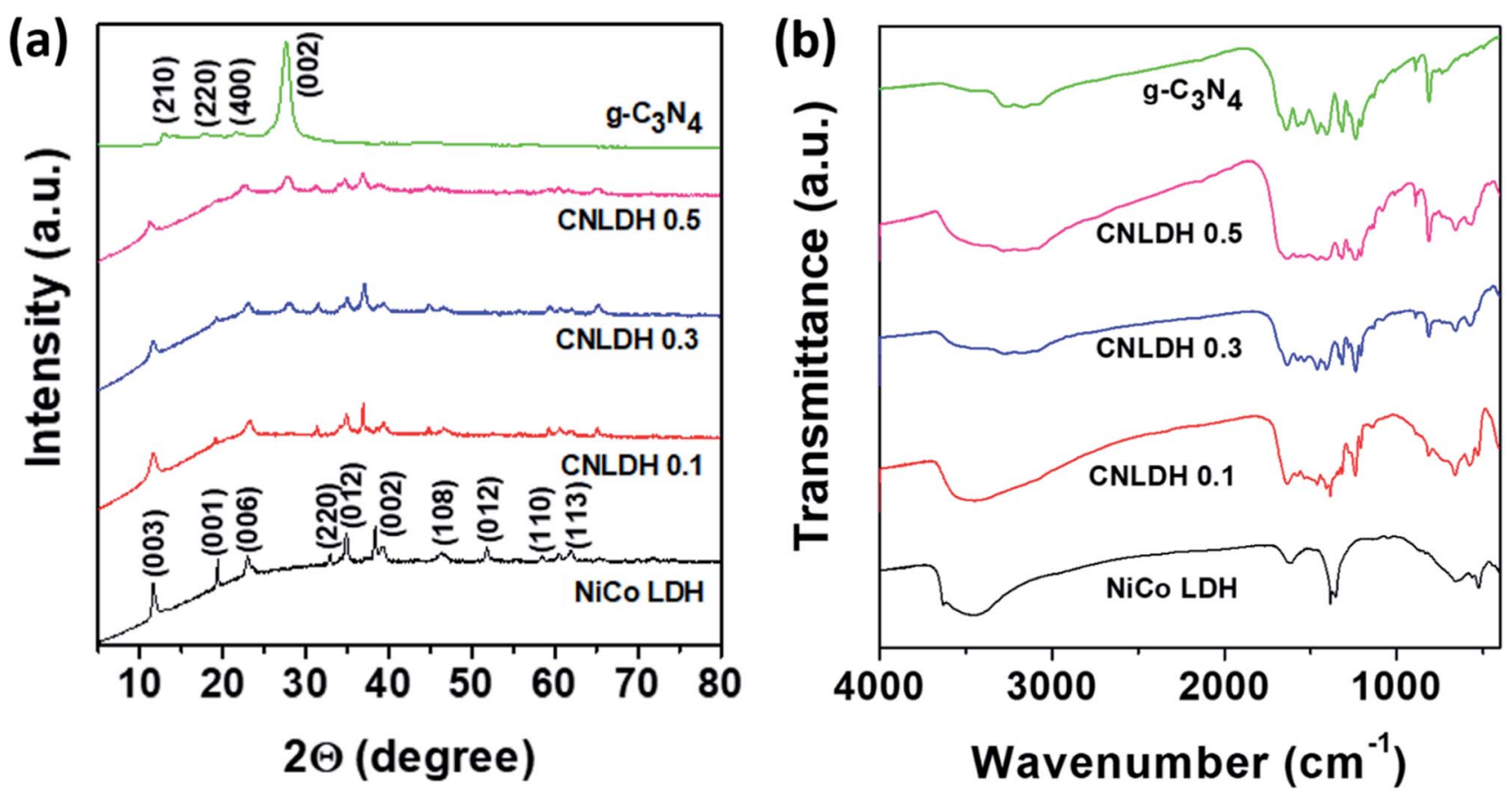

Fig. 3 (a) XRD patterns and (b) FTIR spectra of $\mathrm{g}-\mathrm{C}_{3} \mathrm{~N}_{4}, \mathrm{CNLDH} 0.1, \mathrm{CNLDH} 0.3, \mathrm{CNLDH} 0.5$, and NiCo LDH. 
peaks centered at $398.5,399.6$, and $400.6 \mathrm{eV}$, corresponding to $\mathrm{C}=\mathrm{N}-\mathrm{C}$, tertiary nitrogen $\left(\mathrm{N}-\left(\mathrm{C}_{3}\right)\right)$, and amino functional group having a hydrogen atom, respectively. The synthesis of a defectfree $\mathrm{g}-\mathrm{C}_{3} \mathrm{~N}_{4}$ with the perfect stoichiometric ratio of 0.75 is often challenging. The obtained $\mathrm{C} / \mathrm{N}$ ratio of 0.76 of our $\mathrm{g}-\mathrm{C}_{3} \mathrm{~N}_{4}$ is attributed to the various optimizations carried out along with the systematic reaction design (Table $\mathrm{S} 1 \dagger$ ). ${ }^{38}$ The $\mathrm{C} 1 \mathrm{~s}$ and $\mathrm{N} 1 \mathrm{~s}$ peaks of CNLDH 0.1 confirm the formation of the heterostructure. The binding energies of the $\mathrm{C} 1 \mathrm{~s}$ and $\mathrm{N}$ 1s core electrons remain almost the same, suggesting similar chemical states of carbon and nitrogen (Fig. 4a). However, the percentage of $\mathrm{sp}^{2} \mathrm{C}=\mathrm{C}$ is higher in the hybrid than in $\mathrm{g}-\mathrm{C}_{3} \mathrm{~N}_{4}$ (shown in Fig. 4b), suggesting that tri-s-triazine units were connected with amino groups between the layers. ${ }^{39}$ The $\mathrm{C}-\mathrm{N}-\mathrm{C}$ and $\mathrm{C}-\mathrm{OH}$ peak intensities of CNLDH 0.1 are reduced compared with those of $g$ $\mathrm{C}_{3} \mathrm{~N}_{4}$ indicating the prominent contents of $\mathrm{Ni}$ and $\mathrm{Co}$ ions on $\mathrm{C}-\mathrm{N}-\mathrm{C}$ functional groups of $\mathrm{CN}$. In addition, the positive binding energy shifts of the $\mathrm{C}=\mathrm{N}-\mathrm{C}, \mathrm{N}-(\mathrm{C})_{3}$, and amino $\mathrm{N}$ peaks of CNLDH 0.1 confirm the intercalation between NiCo LDH and $\mathrm{g}^{-} \mathrm{C}_{3} \mathrm{~N}_{4}$ sheets (Fig. 4c). ${ }^{40}$ The presence of elemental $\mathrm{C}$ in the NiCo LDH could be attributed to the residual carbon from the sample and adventitious hydrocarbons from the XPS instrument. The Ni $2 \mathrm{p}$ XP spectrum (Fig. 4 e) shows $2 \mathrm{p}_{3 / 2}$ and $2 \mathrm{p}_{1 / 2}$ peaks at binding energies of 855.6 and $873.2 \mathrm{eV}$, respectively, separated by a binding energy of $17.6 \mathrm{eV}$, which reflects the formation of the NiCo hydroxide. The Co $2 \mathrm{p}$ high-resolution spectrum can be fitted into two doublet spin orbitals of $2 \mathrm{p}_{3 / 2}$ and $2 \mathrm{p}_{1 / 2}$ with two shakeup satellites. In addition, the deconvoluted $\mathrm{O} 1 \mathrm{~s}$ spectrum shows two peaks at binding energies of 530.8 and $533.3 \mathrm{eV}$ attributed to hydroxyl ions and $\mathrm{OH}^{-}$of absorbed molecules, respectively. ${ }^{41}$ The XPS analysis demonstrated that the NiCo LDH nanosheets not only were attached physically on the surfaces of the $\mathrm{g}-\mathrm{C}_{3} \mathrm{~N}_{4}$ sheets, but also formed heterostructures with the $\mathrm{g}-\mathrm{C}_{3} \mathrm{~N}_{4}$ sheets.
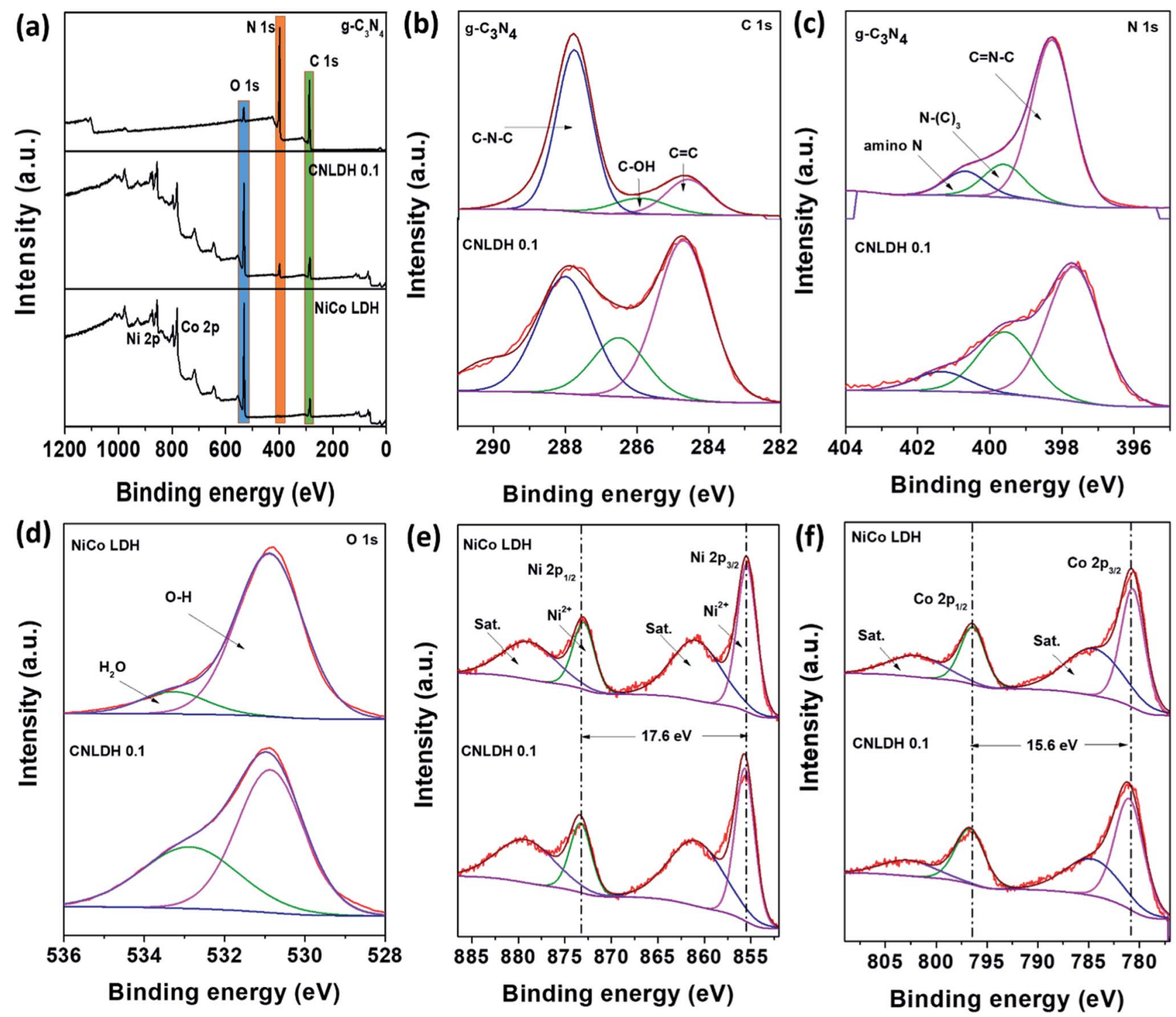

Fig. 4 XP spectra of $\mathrm{g}-\mathrm{C}_{3} \mathrm{~N}_{4}, \mathrm{NiCo} \mathrm{LDH}$, and CNLDH 0.1 . 


\section{BET analysis}

The as-fabricated $\mathrm{g}-\mathrm{C}_{3} \mathrm{~N}_{4}$, NiCo LDH, and CNLDH 0.1 (Fig. S4a, $\mathrm{c}$, and $\mathrm{e}, \dagger$ respectively) exhibit type-IV nitrogen adsorptiondesorption isotherms with large hysteresis loops, indicating the mesoporous structures. The average pore size is reduced upon the addition of $\mathrm{g}-\mathrm{C}_{3} \mathrm{~N}_{4}$ to the NiCo $\mathrm{LDH}$. This can be attributed to the incorporation of NiCo $\mathrm{LDH}$ particles between the pores of the lamellar $\mathrm{g}-\mathrm{C}_{3} \mathrm{~N}_{4}$. Remarkably, the BET specific surface area of CNLDH 0.1 is $69.0 \mathrm{~m}^{2} \mathrm{~g}^{-1}$, approximately three times higher than that of the pure NiCo LDH $\left(24.2 \mathrm{~m}^{2} \mathrm{~g}^{-1}\right)$, which indicates that the introduction of the small amount of $\mathrm{g}-\mathrm{C}_{3} \mathrm{~N}_{4}$ relieves the agglomeration of NiCo LDH layers. Fig. S4b, d, and $\mathrm{f}_{\uparrow}^{\dagger}$ present the pore size distributions of $\mathrm{g}-\mathrm{C}_{3} \mathrm{~N}_{4}$, NiCo $\mathrm{LDH}$, and $\mathrm{CNLDH}$ 0.1 , respectively, showing the average pore sizes of $5 \mathrm{~nm}$.

\section{Electrochemical properties}

The performance metrics of our newly synthesized $\mathrm{g}-\mathrm{C}_{3} \mathrm{~N}_{4}$, NiCo $\mathrm{LDH}$, and $\mathrm{CNLDH}$ heterostructures were evaluated by electrochemical measurements in a three-electrode system. Fig. 5a shows the CV curves of $\mathrm{g}-\mathrm{C}_{3} \mathrm{~N}_{4}$, NiCo LDH, and CNLDH 0.1 at a scan rate of $2 \mathrm{mV} \mathrm{s}^{-1}$. The rectangular $\mathrm{CV}$ curves of $\mathrm{g}-\mathrm{C}_{3} \mathrm{~N}_{4}$ (Fig. S5a $\dagger$ ) in the potential range of 0 to $0.5 \mathrm{~V}$ reveal its doublelayer capacitive electrochemical behavior, whereas the NiCo LDH exhibits Faradaic redox peaks (Fig. S5c $\dagger$ ). The area of the CV curve of CNLDH 0.1 is considerably larger than those of the other electrodes, owing to the higher capacity of CNLDH 0.1 than those of $\mathrm{g}-\mathrm{C}_{3} \mathrm{~N}_{4}$ and NiCo LDH. This is in agreement with the capacities estimated using the GCD curves (Fig. 5d). The CV curve area of the $\mathrm{g}-\mathrm{C}_{3} \mathrm{~N}_{4}$ electrode is very small compared to that of the NiCo LDH, suggesting a very small capacitive contribution of $\mathrm{g}-\mathrm{C}_{3} \mathrm{~N}_{4}$ in $\mathrm{CNLDH}$ 0.1. However, the resultant nanohybrid electrode exhibited a twofold increase in specific capacity compared to that of the NiCo LDH. This could be attributed to the large surface active area provided by $\mathrm{g}-\mathrm{C}_{3} \mathrm{~N}_{4}$ to effectively transfer electrons and restrict the stacking of the LDH. The CNLDH 0.1 electrode exhibited the maximum specific capacity of $183.43 \mathrm{~mA} \mathrm{~h} \mathrm{~g}^{-1}$ at a current density of $1 \mathrm{~A} \mathrm{~g}^{-1}$, higher than those of $\mathrm{g}-\mathrm{C}_{3} \mathrm{~N}_{4}$ and NiCo LDH of $20.89 \mathrm{~mA} \mathrm{~h} \mathrm{~g}{ }^{-1}$ and $95.92 \mathrm{~mA} \mathrm{~h} \mathrm{~g}^{-1}$, respectively. Notably, CNLDH 0.1 exhibits the best specific capacity among those of the previously reported structures presented in Table $1 .^{\mathbf{4 2 - 4 7}}$ The series of optimizations shows that CNLDH 0.1 is superior to CNLDH 0.3 and CNLDH 0.5 (Fig. S6†). Therefore, we use CNLDH 0.1 as a representative sample to discuss the corresponding physical, chemical, and electrochemical properties. Further, the CV curves of the CNLDH 0.1 electrode (Fig. 5b) exhibit a distinct pair of redox peaks at 0.32 and $0.17 \mathrm{~V}$ vs. $\mathrm{Hg} / \mathrm{HgO}$, related to the electrochemical redox reactions of $\mathrm{Ni}(\mathrm{OH})_{2} / \mathrm{NiOOH}$ and $\mathrm{CoOOH} / \mathrm{CoO}_{2}$ in the NiCo $\mathrm{LDH}$, respectively. ${ }^{48}$ With the increase in scan rate, the anodic and cathodic peaks shift toward positive and negative potentials, respectively, owing to the polarization of the electrode. ${ }^{49}$ Charge-discharge curves of CNLDH 0.1 at different current densities are shown in Fig. 5c. CNLDH 0.1 exhibits the highest specific capacity indicating that the content of added g$\mathrm{C}_{3} \mathrm{~N}_{4}$ in the composite is most suitable for the full utilization of the layered $\mathrm{LDH}$ (Fig. $5 \mathrm{~d}$ ). The relation between $C_{\mathrm{sp}}$ and current density shows the higher capacity of CNLDH 0.1 than those of the $\mathrm{g}-\mathrm{C}_{3} \mathrm{~N}_{4}$ and NiCo LDH electrodes at each current density. Moreover, the $C_{\mathrm{sp}}$ values of all samples gradually decrease with (a)

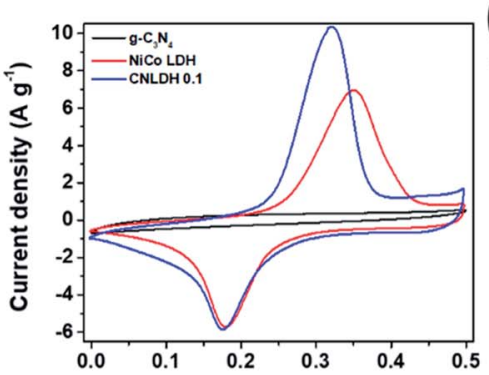

(d)

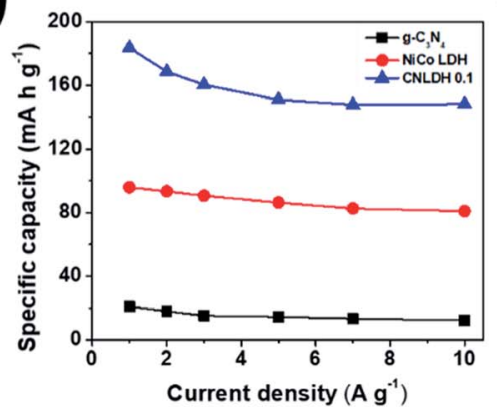

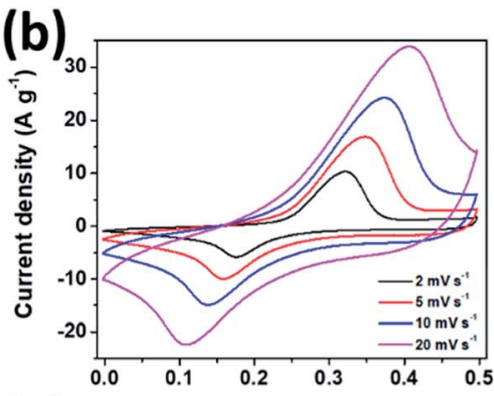

(e)

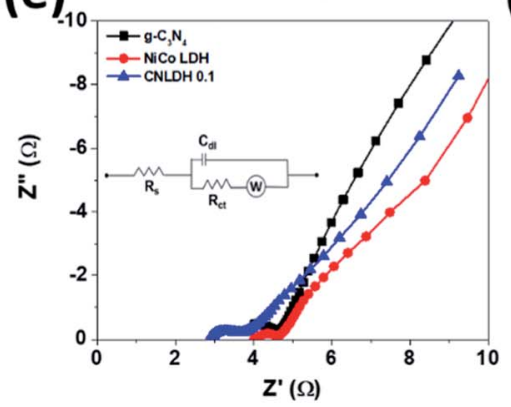

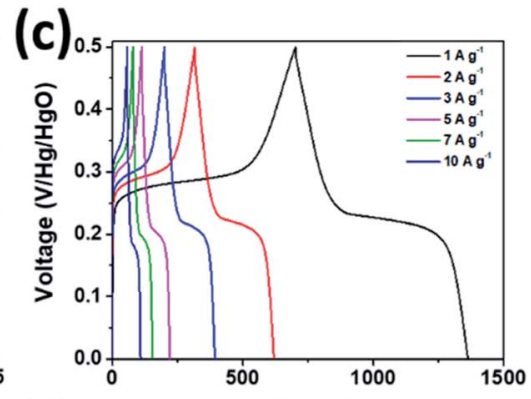

(f)

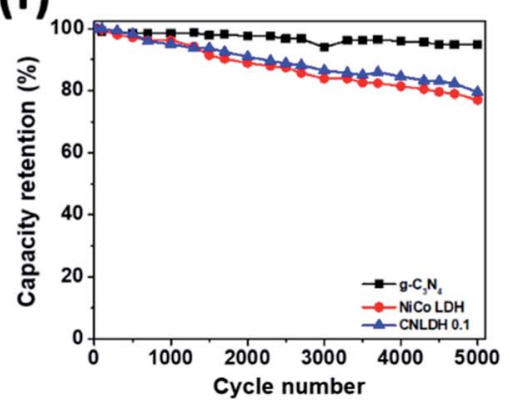

Fig. 5 Electrochemical performances of g- $\mathrm{C}_{3} \mathrm{~N}_{4}, \mathrm{NiCo}$ LDH, and CNLDH 0.1. (a) CV curves of g- $\mathrm{C}_{3} \mathrm{~N}_{4}, \mathrm{NiCo}$ LDH, and CNLDH 0.1 at $2 \mathrm{mV} \mathrm{s}^{-1}$. (b) CV curves of CNLDH 0.1. (c) GCD curves of CNLDH 0.1 at different current densities. (d) Variation in specific capacity with the current density. (e) EIS and (f) electrochemical cyclic stability test results at $10 \mathrm{~A} \mathrm{~g}^{-1}$ in a $6 \mathrm{M} \mathrm{KOH}$ electrolyte for g- $\mathrm{C}_{3} \mathrm{~N}_{4}, \mathrm{NiCo} \mathrm{LDH}$, and CNLDH 0.1. The inset (e) shows the equivalent circuit model used for fitting the EIS spectra. 
the increase in current density. At a low current density, the electrolyte ions have sufficient time to diffuse and well contact the active surfaces for complete reaction, and thus full utilization of the active material.

However, at a high current density, only the external active surface can be utilized for charge storage. ${ }^{50}$ The CNLDH 0.1 nanohybrid electrode retains approximately $76 \%$ of its initial capacity when the current density is increased from 1 to $10 \mathrm{~A} \mathrm{~g}^{-1}$, while that of the pure $\mathrm{g}-\mathrm{C}_{3} \mathrm{~N}_{4}$ decreases to $10 \%$. The NiCo LDH has an excellent rate capability of $81 \%$, which helps improve the rate capability of CNLDH 0.1. Fig. 5e shows the Nyquist plots of pure $\mathrm{g}-\mathrm{C}_{3} \mathrm{~N}_{4}, \mathrm{NiCo} \mathrm{LDH}$, and CNLDH 0.1. An equivalent circuit is used to fit the impedance spectrum (inset Fig. 5e), where $R_{\mathrm{S}}$ represents the solution resistance, $C_{\mathrm{dl}}$ is double layer capacitance, $R_{\mathrm{ct}}$ gives the value of charge transfer resistance, and $W$ is Warburg impedance. The $R_{\mathrm{s}}$ and $R_{\mathrm{ct}}$ values were calculated by reading the real axis intercepts at high frequency region of the Nyquist plot. CNLDH 0.1 shows lower $R_{\mathrm{S}}$ $(2.91 \Omega)$ and $R_{\text {ct }}(3.72 \Omega)$ compared to pure g-C $\mathrm{C}_{3} \mathrm{~N}_{4}\left(R_{\mathrm{S}}=3.71 \Omega\right.$ and $\left.R_{\mathrm{ct}}=4.63 \Omega\right)$ and NiCo LDH $\left(R_{\mathrm{s}}=4.02 \Omega\right.$ and $\left.R_{\mathrm{ct}}=4.67 \Omega\right)$. The superior electronic transport in CNLDH 0.1, attributed to the enhanced interfacial contact by the anchoring of $\mathrm{g}-\mathrm{C}_{3} \mathrm{~N}_{4}$ on the layered material (NiCo LDH). The improved interfacial contact promotes a fast and smooth ion diffusion through the layered structure and decreases its transfer resistance. To evaluate the application feasibility of these materials, the electrochemical cycling stabilities of $\mathrm{g}-\mathrm{C}_{3} \mathrm{~N}_{4}, \mathrm{NiCo} \mathrm{LDH}$, and CNLDH 0.1 were evaluated. Fig. $5 \mathrm{f}$ shows the capacitive stabilities of $\mathrm{g}$ $\mathrm{C}_{3} \mathrm{~N}_{4}$, NiCo $\mathrm{LDH}$, and CNLDH 0.1 at a current density of
$10 \mathrm{~A} \mathrm{~g}^{-1}$. CNLDH 0.1 retains $79 \%$ of its initial capacity after 5000 cycles showing its long-term stability. The corresponding GCD curves are shown in Fig. S7.† The increased electrochemical performances of the CNLDH 0.1 nanohybrid electrode are attributed to the synergetic effect of the $\mathrm{g}-\mathrm{C}_{3} \mathrm{~N}_{4}$ and NiCo LDH 2D nanostructures.

For evaluating the practical application characteristics of CNLDH 0.1 electrode material, a hybrid supercapacitor using CNLDH 0.1 as a positive electrode and activated carbon (AC) as a negative electrode was assembled. Fig. 6 illustrates the electrochemical performance of CNLDH 0.1//AC hybrid supercapacitor in $6 \mathrm{M} \mathrm{KOH}$ electrolyte. From Fig. 6a, it can be seen that the hybrid device expands the working potential window up to $1.2 \mathrm{~V}$. As the hybrid device is the combination of redox electrode and EDLC electrode, the CV curves show rectangular shapes with slightly redox peaks. Fig. $6 \mathrm{~b}$ shows the GCD curves of CNLHD 0.1//AC hybrid supercapacitor at different current densities. The maximum specific capacity of $37.44 \mathrm{~mA} \mathrm{~h} \mathrm{~g}^{-1}$ is obtained at a current density of $1 \mathrm{~A} \mathrm{~g}^{-1}$. The specific capacity at current densities of 2, 3, 5, 7 and $10 \mathrm{~A} \mathrm{~g}^{-1}$ are 30.81, 26.96, 22.51, 18.96 and $14.55 \mathrm{~mA} \mathrm{~h} \mathrm{~g}^{-1}$, respectively (Fig. 6c). The capacity retention of hybrid supercapacitor is $81 \%$ after 5000 cycles at a current density of $10 \mathrm{~A} \mathrm{~g}^{-1}$, showing excellent electrochemical stability of the CNLDH 0.1//AC hybrid supercapacitor. The Ragone plot (Fig. 6e) of CNLDH 0.1//AC hybrid supercapacitor shows the maximum energy density of $22.46 \mathrm{~W} \mathrm{~h} \mathrm{~kg}^{-1}$ at a power density of $600 \mathrm{~W} \mathrm{~kg}^{-1}$. The obtained values of energy density and power density of CNLDH 0.1//AC hybrid supercapacitor are quite remarkable compared to reported hybrid (a)
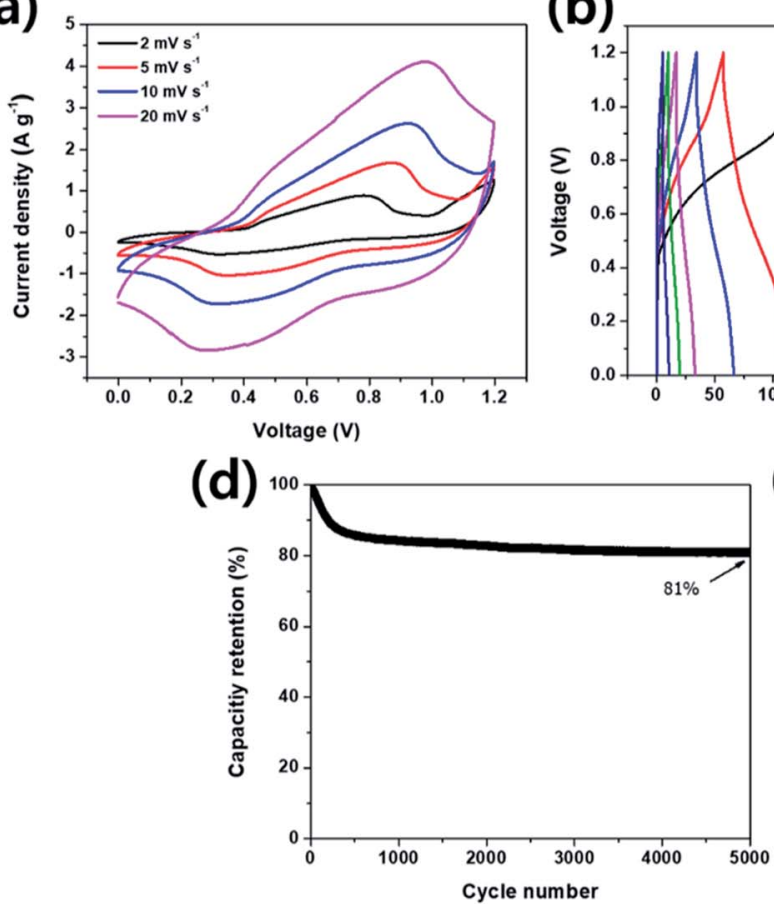

(b)

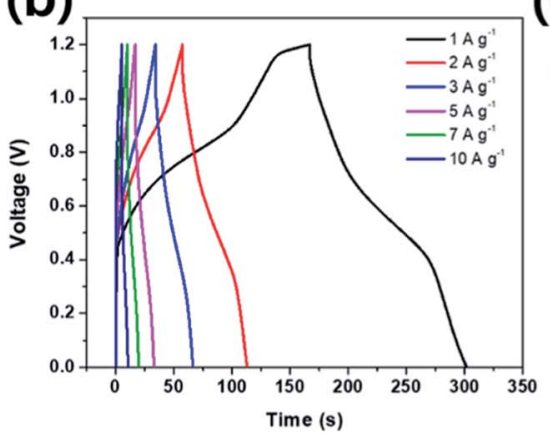

(c)

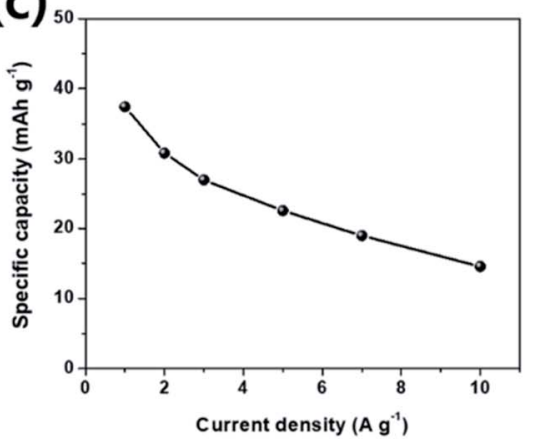

(e)

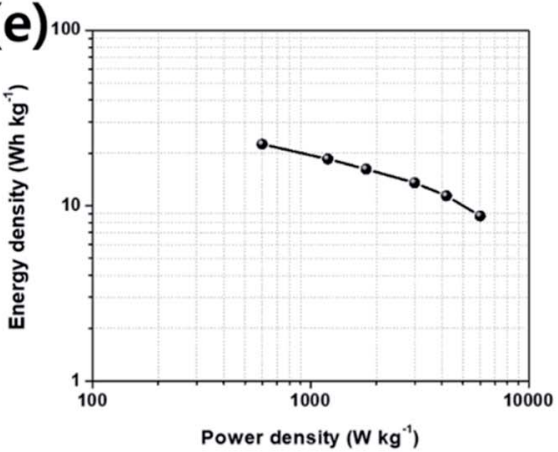

Fig. 6 Electrochemical performance of the CNLDH 0.1//AC hybrid supercapacitor. (a) CV curves at various scan rates within a potential range of 0-1.2 V, (b) GCD curves and (c) corresponding specific capacity at various current densities. (d) Capacity retention at $10 \mathrm{~A} \mathrm{~g}^{-1}$ and (e) Ragone plot of CNLDH 0.1//AC hybrid supercapacitor. 
Table 1 Electrochemical performances of CNLDH 0.1 and previously reported structures

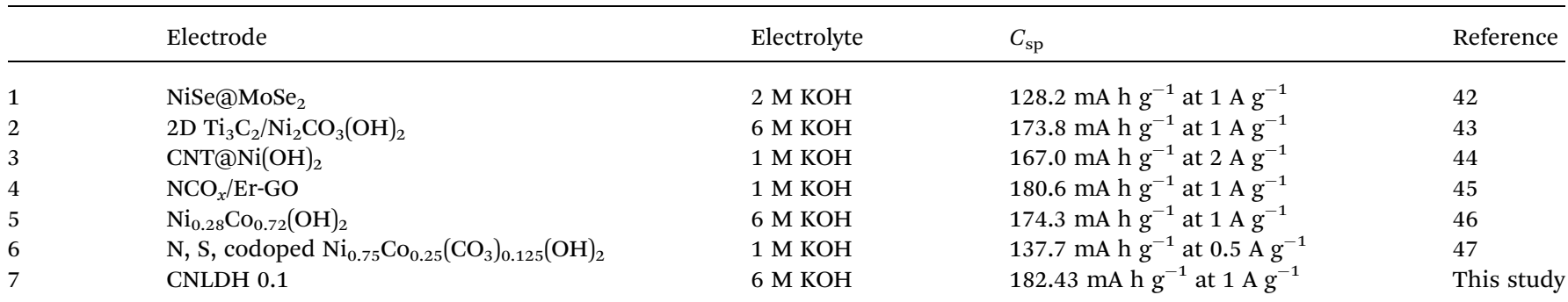

supercapacitor assembly. ${ }^{51-54}$ These electrochemical analyses of CNLDH 0.1//AC hybrid supercapacitor confirm that CNLDH 0.1 nanohybrid is an impressive electrode material for supercapacitor application.

\section{Conclusion}

We presented a simple strategy for the development of CNLDH nanohybrids of $\mathrm{g}-\mathrm{C}_{3} \mathrm{~N}_{4}$ and $2 \mathrm{D}$ NiCo layered materials for supercapacitor electrodes. A series of CNLDH nanohybrids with different mass ratios of $\mathrm{g}-\mathrm{C}_{3} \mathrm{~N}_{4}$ and NiCo LDH was prepared by the hydrothermal method. The structures and morphologies of the nanohybrids suggested that the NiCo LDH nanosheets were in situ-anchored on the surfaces of the $\mathrm{g}-\mathrm{C}_{3} \mathrm{~N}_{4}$ nanosheets or vice versa. CNLDH 0.1 exhibited excellent electrochemical performances, higher than those of CNLDH 0.3 and CNLDH 0.5, owing to the synergetic effect of $\mathrm{g}-\mathrm{C}_{3} \mathrm{~N}_{4}$ and $\mathrm{NiCo}$ LDH. In addition, CNLDH 0.1 exhibited a high specific capacity (182.43 $\mathrm{mA} \mathrm{h} \mathrm{g}^{-1}$ at $1 \mathrm{~A} \mathrm{~g}^{-1}$ ) and long-term cycling stability. The assembled CNLDH 0.1//AC hybrid supercapacitor presented the maximum energy density of $22.46 \mathrm{~W} \mathrm{~h} \mathrm{~kg}^{-1}$ at a power density of $600 \mathrm{~W} \mathrm{~kg} \mathrm{~kg}^{-1}$ and maintained an energy density of $8.73 \mathrm{~W} \mathrm{~h} \mathrm{~kg}^{-1}$ at a high power density of $6000 \mathrm{~W} \mathrm{~kg}^{-1}$. These results indicate that the $\mathrm{CNLDH}$ nanohybrid is a promising material for use as a supercapacitor electrode.

\section{Conflicts of interest}

There are no conflicts to declare.

\section{Acknowledgements}

This research was supported by grants from the Basic Science Research Program through the National Research Foundation of Korea (NRF) funded by the Ministry of Education (2012R1A6A1029029 and 2018R1A2B6009208), Republic of Korea.

\section{Notes and references}

1 Y. Q. Sun, Q. O. Wu and G. Q. Shi, Energy Environ. Sci., 2011, 4, 1113-1132.

2 X. Wu, Y. Zeng, H. Gao, J. Su, J. Liu and Z. Zhu, J. Mater. Chem. A, 2013, 1, 469.
3 C. Zhao, P. Ju, S. Wang, Y. Zhang, S. Min and X. Qian, Electrochim. Acta, 2016, 218, 216.

4 D. U. Lee, J. Fu, M. G. Park, H. Liu, A. G. Kashkooli and Z. Chen, Nano Lett., 2016, 16, 1794.

5 J. Liu, J. Wang, C. Xu, H. Jiang, C. Li, L. Zhang, J. Lin and Z. X. Shen, Adv. Sci., 2018, 5, 1700322.

6 J. A. Wilson and A. D. Yoffe, Adv. Phys., 1969, 18, 193.

7 R. Mas-Ballesté, C. Gómez-Navarro, J. Gómez-Herrero and F. Zamora, Nanoscale, 2011, 3, 20.

8 P. Miró, M. Audiffred and T. Heine, Chem. Soc. Rev., 2014, 43, 6537.

9 A. K. Geim and I. V. Grigorieva, Nature, 2013, 499, 419.

10 K. S. Novoselov, A. Mishchenko, A. Carvalho and A. H. Castro Neto, Science, 2016, 353, 9439.

11 E. Pomerantseva and Y. Gogotsi, Nat. Energy, 2017, 2, 17089. 12 R. Irshad, K. Tahir, B. Li, Z. Sher, J. Ali and S. Nazir, J. Ind. Eng. Chem., 2018, 64, 60.

13 S. A. Han, A. Sohn and S. W. Kim, FlatChem, 2017, 6, 37.

14 R. Zhao, J. Gao, S. Mei, Y. Wu, X. Wang, X. Zhai, J. Yang,

C. Hao and J. Yan, Nanotechnology, 2017, 28, 495710.

15 T. Finge, F. Riederer, M. R. Mueller, T. Grap, K. Kallis and J. Knoch, Ann. Phys., 2017, 529, 1700087.

16 F. Yi, H. Ren, J. Shan, X. Sun, D. Wei and Z. Liu, Chem. Soc. Rev., 2018, 47, 3152.

17 N. Tian, Y. Zhang, X. Li, K. Xiao, X. Du, F. Dong, G. I. N. Waterhouse, T. Zhang and H. Huang, Nano Energy, 2017, 72, 81.

18 L. Peng, Z. Fang, Y. Zhu, C. Yan and G. Yu, Adv. Energy Mater., 2018, 8, 1702179.

19 X. Li, D. Du, Y. Zhang, W. Xing, Q. Xue and Z. Yan, J. Mater. Chem. A, 2017, 5, 15460.

20 Y. Yang, J. Chen, Z. Mao, N. An, D. Wang and B. D. Fahlman, RSC Adv., 2017, 7, 2333.

21 W. J. Ong, L. L. Tan, Y. H. Ng, S. T. Yong and S. P. Chai, Chem. Rev., 2016, 116, 7159.

22 Z. Wu, L. Li, J. Yan and X. Zhang, Adv. Sci., 2017, 4, 1600382. 23 J. Fang, M. Li, Q. Li, W. Zhang, Q. Shou, F. Liu, X. Zhang and J. Cheng, Electrochim. Acta, 2012, 85, 248.

24 J. Yang, J. Zhu, J. Xu, C. Zhang and T. Liu, ACS Appl. Mater. Interfaces, 2017, 9, 44550.

25 O. Guellati, A. Harat, D. Momodu, J. Dangbegnon, T. Romero, D. Begin, C. Pham-Huu, N. Manyala and M. Guerioune, Electrochim. Acta, 2018, 275, 155. 
26 Z. Hu, Y. L. Xie, Y. X. Wang, H. Y. Wu, Y. Y. Yang and Z. Y. Zhang, Electrochim. Acta, 2009, 54, 2737.

27 F. Fina, S. K. Callear, G. M. Carins and J. T. S. Irvine, Chem. Mater., 2015, 27, 2612.

28 H. Dai, X. Gao, E. Liu, Y. H. Yang, W. Q. Hou, L. M. Kang, J. Fan and X. Hu, Diamond Relat. Mater., 2013, 38, 109.

29 J. Yu, S. Wang, B. Cheng, Z. Lin and F. Huang, Catal. Sci. Technol., 2013, 3, 1782.

30 H. Li, F. Musharavati, E. Zalenezhad, X. Chen, K. N. Hui and K. S. Hui, Electrochim. Acta, 2018, 261, 178.

31 G. Nagaraju, G. S. R. Raju, Y. H. Ko and J. S. Yu, Nanoscale, 2016, 8, 812 .

32 T. Guan, L. Fang, Y. Lu, F. Wu, F. Ling, J. Gao, B. Hud, F. Meng and X. Jin, Colloids Surf., A, 2017, 529, 907.

33 F. Cao, M. Gan, L. Ma, X. Li, F. Yan, M. Ye, Y. Zhai and Y. Zhou, Synth. Met., 2017, 234, 154.

34 J. Xu, L. Zhang, R. Shi and Y. Zhu, J. Mater. Chem. A, 2013, 1, 14766.

35 H. Zou, X. Yan, J. Ren, X. Wu, Y. Dai, D. Sha, J. Pan and J. Liu, J Materiomics., 2015, 1, 340.

36 M. Xu, L. Han and S. Dong, ACS Appl. Mater. Interfaces, 2013, $5,12533$.

37 S. W. Hu, L. W. Yang, Y. Tian, X. L. Wei, J. W. Ding, J. X. Zhong and P. K. Chu, J. Colloid Interface Sci., 2014, 431, 42.

38 K. S. Lakhi, D. H. Park, K. A. Bahily, W. Cha, B. Viswanathan, J. H. Choyd and A. Vinu, Chem. Soc. Rev., 2017, 46, 72.

39 P. Qiu, H. Chen, C. Xu, N. Zhou, F. Jiang, X. Wang and Y. Fu, J. Mater. Chem. A, 2015, 3, 24237.

40 T. Wang, S. Zhang, X. Yan, M. Lyu, L. Wang, J. Bell and H. Wang, ACS Appl. Mater. Interfaces, 2017, 9, 15510.
41 T. Guan, L. Fang, Y. Lu, F. Wu, F. Ling, J. Gao, B. Hu, F. Meng and X. Jin, Colloids Surf., A, 2017, 529, 907.

42 J. H. Peng, J. Zhou, K. Sun, G. Ma, Z. Zhang, E. Feng and Z. Lei, ACS Sustainable Chem. Eng., 2017, 5, 5951.

43 J. Guo, Y. Zhao, N. Jiang, A. Liu, L. Gao, Y. Li, H. Wang and T. Ma, Electrochim. Acta, 2018, 292, 168.

44 H. Yi, H. W. Wang, Y. T. Jing, T. Q. Peng, Y. R. Wang, J. Guo, Q. L. He, Z. H. Guo and X. F. Wang, J. Mater. Chem. A, 2015, 3, 19545.

45 A. Adán-Mása, T. M. Silvaa, L. Guerlou-Demourguesb, L. Bourgeoise, C. Labrugere-Sarrosteg and M. F. Montemora, J. Power Sources, 2019, 419, 12.

46 Y. Tang, Y. Liu, S. Yu, W. Guo, S. Mub, H. Wang, Y. Zhao, L. Hou, Y. Fan and F. Gao, Electrochim. Acta, 2015, 161, 279.

47 F. Wen, Y. Zhang, X. Qian, J. Zhang, R. Hu, X. Hu, X. Wang and J. Zhu, ACS Appl. Mater. Interfaces, 2017, 9, 44441.

48 Q. Zhou, X. Wang, Y. Liu, Y. He, Y. Gao and J. Liu, J. Electrochem. Soc., 2014, 161, A1922.

49 Y. B. Vogel, L. Zhang, N. Darwish, V. R. Gonçales, A. L. Brun, J. J. Gooding, A. Molina, G. G. Wallace, M. L. Coote, J. Gonzalez and S. Ciamp, Nat. Commun., 2017, 8, 2066.

50 J. Zhang, W. Yang and J. Liu, Electrochim. Acta, 2016, 209, 85. 51 X. Wang, A. Sumboja, M. F. Lin, J. Yan and P. S. Lee, Nanoscale, 2012, 4, 7266.

52 X. Yu, B. Lu and Z. Xu, Adv. Mater., 2014, 26, 1044.

53 B. Senthilkumar, D. Meyrick, Y. S. Lee and R. K. Selvan, RSC Adv., 2013, 3, 16542.

54 A. D. Jagadale, G. Guan, X. Li, X. Du, X. Ma, X. Hao and A. Abudula, J. Power Sources, 2016, 306, 526. 